\title{
Groups, Commons and Regulations: Experiments with Villagers and Students in Colombia"
}

\author{
(This Draft: August 16, 2004) \\ Juan Camilo Cardenas ${ }^{1}$ \\ Facultad de Economía - Centro de Estudios sobre Desarrollo Económico CEDE \\ Universidad de Los Andes \\ jccarden@uniandes.edu.co \\ International Fellow \\ The Santa Fe Institute
}

Presented for a volume on

"Psychology, Rationality and Economic Behavior: Challenging Standard Assumptions" edited by Bina Agarwal and Alessandro Vercelli (International Economics Association) 


\section{Introduction}

Group externalities imply a situation where individual and group interests are not aligned and therefore require the design of rules or institutions that correct the failure in order to improve social outcomes. Public goods, team work, the use of natural resources under joint access, or any other pollution problem are examples of such potential divergence between individual and group incentives. Institutional corrections can come exogenously from a regulatory state that brings in command \& control or incentive mechanisms (pecuniary or not-pecuniary), or that reassigns property rights to correct the failure. But solutions can also emerge endogenously from the group, through self-governed institutions, with similar mechanisms of material or non-material incentives, as well as social norms or conventions.

To solve the dilemma, that is, to induce individuals to make decisions that are both individually rational and socially efficient, we need to set up institutional mechanisms that are cost-effective. But the design and enforcement of such mechanisms are likely to involve a range of costs, such as those associated with the design of the instrument, with the gathering of information about compliance and non-compliance, and with punishing violators and/or rewarding those complying with material or non material incentives. But if these costs are sufficiently high, we cannot guarantee full compliance when the regulator - whether from the group or external - has incomplete information, and there is thus room for opportunistic behavior on the part of the agents.

Nevertheless, as we will observe from the experimental results reported here, and from the expanding literature on other-regarding preferences (Bowles, 1998; Gintis, 2000; Camerer and Fehr, 2004; Fehr and Schmidt, 1999), there are still possibilities of pro-social or group-oriented behavior, even in the absence of any enforceable mechanism, which can help solve the conflict between individual and group interest. Basically, without perfectly monitored and cost-effective enforcement, the ability of any partially enforceable institution to solve the dilemma will ultimately depend on individual willingness to follow the social norm. This would solve the problem of coordination failure, given the asymmetries of information between the regulator and the group members. This is true for both an external regulator (e.g. the state) and an endogenous one (e.g. a community organization). Both can only partially observe the level of cooperation in collective action, and the level of compliance of any new mechanism that is introduced.

The behavioral focus here is twofold. On the one hand, this chapter will explore what choices individuals (as regulated agents) make when an external regulation is introduced to solve the problem of coordination failure. On the other hand, it will examine how individuals respond when asked, through a voting mechanism, about their preferences toward the application of such mechanisms by an external regulator, e.g. the state.

This paper seeks to make a small contribution by testing some of the behavioral hypotheses under different regulations, with an experimental design tested both in the field and in the university lab. Although the experimental literature has explored several behavioral phenomena associated with monitoring and sanctioning, many of these have focused on sanctioning by the same group members, by allowing players to reduce or increase the income of other players, depending on their 
cooperative behavior. The mechanisms through which individuals are willing to punish free-riders, at a personal cost, has been studied extensively, including by Carpenter (2004) and Carpenter and Mathews (2004) who suggest that there is a demand for punishment in people's utility function. Andreoni et.al (2003) also study the individual and combined effects of rewards and sanctions, showing that in combination they can be effective in inducing individuals to increase social efficiency in a proposer-responder game. But again, it is the players themselves who assume the cost of rewards and sanctions, rather than an external agent.

The path taken here, however, departs from these approaches. ${ }^{2}$ First, we wanted to study the behavioral consequences of external regulators introducing rules to induce agents to become more cooperative. Second, we wanted to introduce the problem of imperfect monitoring in which the regulator cannot observe or sanction more than a fraction of the players. These conditions seem to resemble many instances in which government agencies can only partially monitor the behavior of agents in order to sanction those not complying with a socially oriented norm.

Besides finding behavioural differences between college students and people in the field, which should be of interest to those using experimental methods in general, the results suggest that even if a majority of players vote against the rules to enforce a socially optimum outcome, they are still willing to cooperate and reduce over extraction, as suggested by the regulations tested. Further, the data do not entirely support the symmetric Nash equilibrium predicted by a model of the expected costs of different regulations. Players do not respond substantially to changes in the size of the penalty. Also, differences across the sites we studied might explain attitudes towards the rules, the rulers and the compliance levels.

Section 2 below will describe the village context where the field experiments were conducted. Section 3 presents the theoretical model and experimental designs. Section 4 presents the results and the concluding Section 5 will outline some implications.

\section{The field context}

The experiments and fieldwork were conducted during 2000-2003 in ten different sites across Colombia. For the entire sample of sessions we randomly distributed different regulations and payoff structures among almost twenty different experimental treatments.. The treatments reported here were run in five of these villages after making sure that within each village at least three sessions of exactly the same treatment were conducted. In all sites we recruited participants that had some dependence on a natural resource for which there was joint access, although individually such dependence could vary within a site. The five sites, in alphabetical order, for this sample are described below. ${ }^{3}$

In the dam reservoir of Neusa, about $100 \mathrm{~km}$. North of Bogotá in the Andean region, a group of farmers have been engaged in trout fishing mainly to sell in the local markets and restaurants, keeping a small proportion for self-consumption. They have been experiencing a fall in the resource stock due to over fishing and competition from sport fishermen. The regional environmental authority has been introducing stronger regulations on catch size and quotas, as well as reintroducing trout populations, given that trout cannot reproduce naturally in these settings. About 
40 farming households directly participate in this activity while farming their own land alongside, and dozens come during the week and weekends for sport fishing.

In the Island of Providencia, in the Caribbean coast of Colombia, we invited those who participate in two main economic activities of extraction. One group we invited was of fishermen that catch several species in the coral reefs and coastal waters for selling to passing boats and local markets, as well as for self-consumption. The other group we invited regularly gathers crabs that circulate between the inland and the beach. They sell these to the local restaurants that cater to tourists and also gather some for self-consumption. In both cases, fishing and crab catching, there are regulations that are partially enforced by the regional authority. In addition, there are a few informal and community agreed rules for self-monitoring catch sizes and location rotations, by seasons.

In the southern Pacific coast of the country we find the National Natural Park of Sanquianga, composed mostly of mangrove forest that provides a multiplicity of goods and services to people spread in small settlements constituted of a few dozen or a few hundred households. They allot most of their time to fishing and gathering other products from the coastal areas such as fish, clams, firewood, crabs, and so on. We particularly recruited people that extract a mollusk or clam (anadara tuberculosa) which provides food and income but which has also been suffering from over extraction and a declining market over the years. The officers of the National Park regulate the area through a few weakly enforced rules issued by the national and regional environmental authorities and a few agreements with communities and organized groups. They seek to limit catch sizes, nets types and sizes, and to enforce the closed season for some of the resources by biological seasons.

In the community of Tabio, about $50 \mathrm{~km}$ northwest of Bogotá and also in the Andean mountains, a few hundred farmers and rural households depend on the natural supply of water from their local watershed. A remaining fraction of households extract firewood from these forests for cooking. The supply of water depends highly on the natural vegetation, and the local municipality and regional authorities try to enforce a set of rules for the buffer zones along the watershed, which is mostly located within private property.

In the Andean forest about $150 \mathrm{~km}$ west of Bogotá, at an elevation of around 1,500 meters we find the village of La Vega where farmers share a watershed and need to make decisions about land use, afforestation and firewood extraction along with decisions relating to their agricultural and livestock practices, and especially regarding coffee production, which requires water for irrigation and coffee beans processing. These activities create organic emissions downstream. The supply of water is highly dependent on the management of the natural forest especially upstream where the water springs are located. The local committee of coffee growers has been working with local authorities and farmers' associations to undertake training and technological transfer activities to make a better use of the forested area around the watershed and improve the quality of resources, increase and sustain the supply of firewood and continue afforestation by planting native species.

In all five cases we invited adults (18 years and above) to participate in the experiments. No two people from the same household were allowed to participate in the same session. We also tried to recruit people from all socio-economic levels in the villages. About half of the total participants were females, but depending on the resource and location, our sample could have a selection bias: for instance, in the case of Providencia most fishery activities are conducted by men and most crab gathering by women. However, no significant gender effect was found in experimental behavior. 
We found some common patterns across the sites. We have rural households that depend in some degree on a joint access natural resource that is used for self-consumption and/or market sale. We observe that households must allocate their resources (labor, land, equipment) into private activities and extractive activities. This leads to an inherent paradox: on the one hand extracting more of the resource enhances individual well-being. On the other hand at an aggregate level, more extraction produces negative externalities for the community as a whole. In all cases there is a regulatory agency that partially enforces some rules that limit extraction or use of the resource, but we observe that the monitoring and enforcement costs affect compliance.

\section{The experimental and field approach.}

There is an extensive theoretical, empirical and experimental literature on the study of self-governed solutions to dilemmas such as the "tragedy of the commons". Much of this literature has been catalyzed by Hardin's postulates in the late 1960's. Writings by Berkes (1989), Ostrom (1990), Ostrom, Gardner and Walker (1994), and Baland and Platteau (1996) are seminal works on the topic, that have helped us qualify the conditions that seem to predict or reject the tragedy. More recent work which combines and contrasts experimental, theoretical and field-based analysis provides a wide set of conditions under which individuals may confirm or reject the original tragedy scenario (Ostrom et.al 2002). Many of these factors are related with technology in the group production function, or with the relative marginal returns from group production, or with the private or exit options of group members, or with the surrounding conditions that provide an ecological or cultural environment for the emergence of certain norms of cooperative behavior.

The experimental literature on voluntary contributions to a public good, or the extraction of a common-pool resource suggests that individuals respond with a wider set of strategies than those predicted from a simple game-theoretical solution based on the maximization of net personal material gains (Ledyard, 1995; Ostrom, Gardner and Walker, 1994). In fact some are willing to cooperate even in one-shot anonymous settings. However, in the absence of any institution that coordinates individual actions, the tendency in a repeated game is for free-riding to increase over time and lead to less socially optimal equilibria. The most plausible explanation for this is that when players see others become more opportunistic it induces a reciprocal response, which decreases social efficiency over time.

Regulatory agencies can design various mechanisms to induce a change in the incentives of the players and so improve group outcome or decrease over extraction of a common-pool resource. Assuming that the regulator wants to maximize the group outcome ${ }^{4}$, it can introduce a regulation that imposes a cost on individuals who act in ways that reduces the group outcome. The severity of the cost can be made variable by changing the level of monitoring or enforcement, the level of the fine or penalty, or the way the regulated players participate in the decision to impose or not to impose such a mechanism.

As a baseline scenario, the regulator can assume that under a non-regulated and non-cooperative game, players make their decisions based on a Nash strategy that maximizes their individual material payoffs. The regulator can, for instance, impose a cost on certain decisions so that the new material 
payoffs (that include the expected cost of the regulation) induce a new Nash strategy that achieves more efficient outcomes for the group. However, unless the regulator can fully enforce the new rule by monitoring all players, there might be risks for opportunistic behavior by players that over-extract the commons incorporating into their calculations the probability of not being inspected and therefore benefit from the compliance of others. As the fraction of players following this opportunistic strategy grows, the aggregate extraction of the resource brings the common-pool to socially inefficient levels.

One problem with regulations designed at shifting behavior towards optimal group outcomes is that they assume players behave as predicted by the bomo economicus model of behavior, in which individuals follow an optimizing strategy based solely on their own material payoffs, including the expected costs of the regulation. However, economic decisions are also affected by other factors, such as emotions, social norms, reciprocity, inequality aversion, lack of complete information and lack of perfect calculating capabilities, among others, as behavioral and experimental economists have demonstrated (Kahneman and Tversky, 2000; Rabin, 1998, 2002; Fehr and Schmidt, 1999; Loewenstein, 1999).

In Cardenas et.al (2000) we tested such hypotheses by conducting a series of experiments in the field with several groups of eight villagers who in their daily lives face the problem of joint access to a natural resource. First, the results showed that players did not choose their best Nash response during the first stage of a repeated number of rounds, where no regulation or coordination was allowed among the players. Second, and more interestingly, during the second stage when a new rule was introduced that imposed a fine proportional to the level of extraction, with a probability of $1 / 16$ to be enforced for each of the eight players, the effectiveness of the regulation was very high in the first rounds. But with subsequent rounds group behavior became increasingly individualistic, lowering the levels of cooperation even below those achieved during the first stage with no regulation at all.

These factors that affect behavior, should also be taken into account when designing regulations aimed at guiding or shifting rational individual behavior away from socially inefficient decisions. The experimental literature has explored the effects of regulations and explicit economic incentives in common-pool public goods and other social dilemmas settings, but most use university students as their main subjects. Further, much of the experimental work on the role of monitoring and sanctioning has focused on mechanisms that are endogenous to the group, that is, the group members are assumed to take on the cost of monitoring or even reducing the penalization of freeriders. ${ }^{5}$

However, there is surprisingly little work on situations where external regulators enforce rules aimed at correcting group externality, despite the fact that in many field settings where groups depend on a common-pool resource it is usual to have an external authority that devices and implements regulations based on incentives, or on command and control. Furthermore, although experiments on regulations and incentives have now been conducted for some time, barring those undertaken in 1998 by Cardenas et al (2000), few such experiments have been done in field settings where the subjects in real life face the theoretical problem in question. ${ }^{6}$

This paper explores individual decision-making under such economic settings by bringing the experimental lab to the field and compares the results with the experiments involving students. In 
particular, I will focus on changes in individual decisions concerning resource extraction and their effects, after introducing external regulatory mechanisms aimed at solving the dilemma. I will also examine individual preferences for such external regulatory mechanisms.

The design is based on a simple model of a group of natural resource users who face a group externality, to test the effects of regulations and rule enforcement in these dilemmas. The experimental situation is framed as one where a group of five people can extract resources from the same source to which they have joint access (see appendix for protocols and instructions read to the participants). Individuals derive part of their payoffs (direct benefits) from putting effort into extracting a resource (e.g. firewood). They also see their payoffs (indirect benefits) reduced in terms of, say, a fall in water quality or a loss of biodiversity from the negative externality that occurs as the group's aggregate extraction increases, because of over extraction from the common pool. In each of our experimental sessions, over 20 rounds, five participants must decide the level of resource extraction, where individual extraction increases payoffs but in aggregate terms the extraction reduces your own and the others' payoffs. The design based on repeated rounds will allow players to understand this incentive structure and form conjectures of what the rest of the players in their group would do within the particular set of rules.

For the last 10 rounds we introduced a rule aimed at achieving the social optimum by using an explicit material cost to individual over-extraction, but the monitoring of the rule was stochastic and incomplete, that is, only one of the players was monitored and actually faced the fine or penalty if extraction was above the permitted level. We altered the penalty, as well as the way the rule was decided (mandatory or through group voting and applied it only if a majority approved). We then compared these treatments with a baseline one where for the 20 rounds the participants were not allowed to communicate, nor did they face any kind of regulation.

All sessions in the field and the university were hand-run, using pencil and paper. Each session took about 3 hours. This included the time taken for reading the protocols (see Appendix), running 2 or 3 practice rounds, undertaking two stages of 20 rounds, and calculating the earnings by subject while they filled out a short exit survey and other demographic details.

\section{Field application of an experimental design}

Between 2000 and 2003 we conducted a long series of economic experiments in the five rural sites mentioned in section 2, with 320 villagers that depended on common-pool resources on a daily basis. We also conducted the same experiments with 105 college students in order to compare and derive some lessons regarding the use of these methods both in the lab and in the field.

\section{The Non-cooperative game}

Assume $\mathrm{n}$ players that benefit from the forest, and who each have the same maximum labor endowment of $e$ units to allocate in extracting a particular resource. Player i's level of extraction $\mathrm{x}_{\mathrm{i}}$, with $0 \leq \mathrm{x}_{\mathrm{i}} \leq e$, increases her payoffs at a decreasing rate (direct extraction benefits $=\mathrm{a} \mathrm{x}_{\mathrm{i}}-1 / 2 \mathrm{~b} \mathrm{x}_{\mathrm{i}}^{2}$, $\mathrm{a}, \mathrm{b}>0)$, while the aggregate extraction by the $\mathrm{n}$ players $\sum \mathrm{x}_{\mathrm{i}}(\mathrm{i}=1, \mathrm{n})$, reduces $\mathrm{i}^{\prime}$ s payoffs (indirect 
benefits $\left.=\sum\left(e-x_{i}\right),>0\right)$. The externality can also be described as a public good benefit from conservation, i.e. lack of extraction. Thus, player i's payoffs are:

$$
\pi_{\mathrm{i}}=\left(\mathrm{ax}_{\mathrm{i}}-1 / 2 \mathrm{bx}_{\mathrm{i}}^{2}\right)+\alpha \sum\left(\mathrm{e}-\mathrm{x}_{\mathrm{i}}\right)
$$

For $\mathrm{n}$ players, and assuming symmetric endowments for all, $e$, we can rewrite [1] as [2],

$$
\pi_{\mathrm{i}}=\mathrm{ax}_{\mathrm{i}}-1 / 2 \mathrm{bx}_{\mathrm{i}}^{2}+\alpha \mathrm{ne}-\alpha \sum \mathrm{x}_{\mathrm{i}}
$$

If player $i$ chooses $x_{i}$ to maximize $\Pi_{i}$, the first order conditions that produce the optimal level of extraction $\mathrm{x}_{\mathrm{i}}^{\text {nash }}$ are $\partial \pi_{\mathrm{i}} / \partial \mathrm{x}_{\mathrm{i}}=\mathrm{a}-\mathrm{bx}_{\mathrm{i}}-\alpha=0$, which requires that:

$$
\mathrm{x}_{\mathrm{i}}^{\text {nash }}=(\mathrm{a}-\alpha) / \mathrm{b}, \text { for } 0 \leq \mathrm{x}_{\mathrm{i}} \leq e
$$

For example, suppose values of $e=8, a=60, b=5$, and $\alpha=20, x_{i}^{\text {nash }}=(a-\alpha) / b=8$. From the standpoint of any player it would be a Nash best response -and a dominant strategy, to allocate maximum labor for extracting from the forest. Later we choose parameters that allow us to create the environment of incentives we need for our experimental design.

To produce the socially efficient outcome, we maximize the aggregate payoffs [4] and calculate the optimal level of extraction for the individuals, $\mathrm{x}_{\mathrm{i}}^{\mathrm{so}}$.

$$
\mathrm{W}=\sum \pi_{\mathrm{i}}=\sum \mathrm{ax}_{\mathrm{i}}-1 / 2 \mathrm{~b} \sum \mathrm{x}_{\mathrm{i}}^{2}+\alpha \mathrm{n}^{2} e-\alpha \mathrm{n} \sum \mathrm{x}_{\mathrm{i}}
$$

The first order conditions, $\partial \mathrm{W} / \partial \mathrm{x}_{\mathrm{i}}=\mathrm{a}-\mathrm{b} \mathrm{x}_{\mathrm{i}}-\alpha \mathrm{n}=0$, which requires that:

$$
\mathrm{x}_{\mathrm{i}}^{\mathrm{so}}=(\mathrm{a}-\alpha \mathrm{n}) / \mathrm{b}, \text { for } 0 \leq \mathrm{x}_{\mathrm{i}} \leq e
$$

For the same parameters as above, and for a group of $n=5$ players, such a solution would require each player to allocate $(60-5 * 20) / 5<0$. Since $x_{i}$ takes only nonnegative values, for framing the experimental design we have a corner solution at $\mathrm{x}_{i}^{\mathrm{so}}=0$, i.e. players should not allocate labor into extraction to produce the socially efficient outcome. We have eliminated in the table the option of $\mathrm{x}_{\mathrm{i}}^{\mathrm{so}}=0$ to avoid possible conflicts in conducting these experiments in the field. Previous experiments and pre-testing exercises suggest that there is a strong aversion toward prohibition of resource use that could create problems with our participants when conducting the experiments this way. Interior solutions with non-dominant strategies, such as used in OGW (1994) and Cardenas et.al (2000), are another alternative, but here too we have decided to maintain corner solutions in order to have a design with a dominant strategy.

The payoffs for these parameter values are given in the appendix as the payoffs table that was used in the field for the experiments. The values in the cells are the earnings in one round. This table was handed to the five participants in each group. In each round, each person should decide the level of extraction between 1 and 8 units, and the earnings can then be calculated if we know the total group effort expended in extracting, by looking at the respective column and row in the table. For instance, if player $i$ follows the group maximizing strategy $x=1$, individual earnings are $\$ 745$ given that i's 
extraction is 1 unit and "their extraction" is 4 units. If all players follow the Nash dominant strategy, $x=8$, each player will obtain $\$ 320$ in that round.

\section{External regulation of individual behavior}

Following the analysis of external regulation in Cardenas et.al (2000) we introduce a regulation in the form of a penalty $f$ (cost), externally imposed with certain probability $p$, to individual allocations above that required for the social optimal solution. By varying the probability of inspections times the fine or penalty we will test weak and strong enforcement levels. The treatments will also include applying the regulation exogenously (by the monitor), and endogenously (voted by the group).

Following from equation [2], the new expected payoff function for a player $\mathrm{i}$ is then:

$$
\pi_{\mathrm{i}}=\mathrm{ax}_{\mathrm{i}}-1 / 2 \mathrm{bx}_{\mathrm{i}}^{2}+\alpha \mathrm{n} e-\alpha \sum \mathrm{x}_{\mathrm{i}}-\not p\left(\mathrm{x}_{\mathrm{i}}-\mathrm{x}_{\mathrm{i}}^{\mathrm{so}}\right)
$$

which yields the FOCs: $\partial \pi_{\mathrm{i}} / \partial \mathrm{x}_{\mathrm{i}}=\mathrm{a}-\mathrm{bx}_{\mathrm{i}}-\alpha-\not f=0$, which requires that:

$$
\mathrm{x}_{\mathrm{i}}^{\text {nash-REG }}=(\mathrm{a}-\alpha-\not f) / \mathrm{b}, \text { for } 0 \leq \mathrm{x}_{\mathrm{i}} \leq e
$$

Suppose that for the weak enforcement case the probability of inspection is of $p=1 / 5$ and the fine $f=50$. Here the best response, based in the expected cost of the regulation, should be $x_{i}^{\text {nash-REG }}=6$ units, which would only partially increase earnings. In the case of a strong regulation for a fine of $f=175$ points, we get $x_{i}^{\text {nash-REG }}=1$ unit, which would achieve the socially optimal solution by aligning the best response function with the socially optimal condition.

\section{Field Experiment design}

The experiments were all conducted for groups of five players, in a finite repeated game of 20 rounds, divided into two stages of 10 rounds each. The players' payoffs, according to the above model and the payoffs table included in the appendix, increase with the individual's level of appropriation but decrease with the aggregate level of use by the group, following the incentives structure of any group externality dilemma. Throughout the game all decisions are made individually and privately and only the groups' outcome is publicly announced in each round. The first stage (rounds 1-10), for all groups, will be under a baseline treatment as a non-cooperative game, where each subject decides individually and privately her level of appropriation of the commons according to the payoffs incentives described earlier. In the second stage (rounds 11-20) a new institution is introduced in the form of a regulation aimed at improving social earnings. Different forms of regulation were tested by varying the severity of the regulation (high vs low), and the enforcement mechanism (exogenous vs endogenous).

For the second round we explicitly told the players (a) that if each player chose to extract 1 unit the group would get the maximum earnings possible, and (b) that to enforce such a rule we would introduce a regulation by randomly choosing a player and applying a fine to the inspected player based on her deviation from the socially optimum solution. We varied the size of the fine, and the mechanism for introducing the regulation by allowing some groups to vote for the external 
regulation. We compared these treatments with the baseline where no new rule is introduced during the second stage. The details of how the stages were conducted follow.

Pre-game stage (Instructions and practice rounds)

Each of the experiments begin by reading the instructions to the group of five players, and handing the experimental forms to each of them (see appendices): GAME CARDS [yellow] where they make their choice in each round, DECISIONS RECORDS SHEET [green] for their own calculations and record-keeping, and the PAYOFF TABLE [blue]). Once all questions from participants are clarified, the experimenter conducts one demonstration round and one more practice rounds. After answering the questions, stage 1 begins.

$\underline{\text { Stage } 1 \text { (Rounds 1-10) }}$

In stage 1 of the experiment each player must decide privately her/his level of individual extraction from the commons, and write this down in a yellow round card; the same information is also recorded in the blue records sheet. The monitor collects the 5 cards, adds the total extraction for the group which he writes in the monitor's record sheet, and announces the total publicly. Each player must write the group's total, and by subtracting her/his individual extraction s/he is able to calculate the payoffs for that round. S/he writes her/his total gains for the round and the experiment proceeds to the next round by filling a new card.

Stage 2 (New rule, Rounds 11-20):

During stage 2 we introduce the different forms of regulation of the use of the commons by varying the severity (high, low) of the regulation and the type (exogenous, endogenous) of enforcement. The stage will typically begin by an announcement from the monitor describing a new regulation to be enforced in each round aimed at producing the socially optimal point where the group's earnings are maximized, that is $\mathrm{X}_{\mathrm{i}}=1$.

For all regulation treatments, the monitor began reading the instructions in the second stage by saying explicitly that by then all players would have noticed that the group can earn the maximum of points if all players chose to extract 1 unit only and that the new rule was aimed at producing such an outcome. Then the monitor continued with the details on how each different rule was to be administered. A portion of the groups were told that through a one-time vote they could decide by a simple majority ( 3 or more votes) to have such regulation applied to them from then on. For a portion of the groups the regulation was mandatory.

There were also control groups for a baseline treatment with no change in the rules for the second stage and where no mention was made of a socially desirable set of individual choices. Such baseline groups were not allowed to have any communication either.

The regulations were administered in the following way. After all players had calculated their earnings for a specific round, a player was chosen randomly from the group, followed by an inspection by the monitor to verify compliance with the new rule. If the majority of the group voted against the application of the regulation, the monitor would conduct the remaining rounds in the second stage in the same manner as in the first stage. However, the monitor would have told these 
groups about the rule to achieve the social optimum through each player choosing 1 unit of extraction.

For groups that had voted in favor of external regulation, or that had faced the same but mandatory rule, the inspection worked as follows. If there was compliance, the monitor would continue the experiment to the next round. If the inspected player chose more than 1 unit of extraction, the monitor would subtract from her total earnings the penalty $p$ times the number of units in noncompliance. Once the player was selected publicly, the rest of the procedure was conducted in private between the monitor and the player, that is, the rest of players in that round did not know what was actually chosen by the inspected player, nor her level of compliance or the penalty applied. Then the experiment proceeded to the next round until stage 2 was completed.

Exit stage (Calculate earnings, fill out survey):

After the completion of all stage 2 rounds, the monitors calculated the total earnings for each player by adding the column of the earnings from the round and subtracting the cases where a fine was imposed. While the monitor made the calculations, the players responded to the exit survey anonymously and in private. Then payments were made privately in cash to each player, on the return of the filled out survey.

\section{Community workshops:}

After all experiments had been conducted in each of the villages, and the research team had taken a day off for data analysis, a community workshop was held with all participants and other interested villagers for the presentation of the results, discussions about their plausible explanations, and the relation of the experiments with the institutional context of the village regarding the use of the commons and their regulation. In other words, the workshop helped in the collection of analytical stories about the internal and external validity of the experiments, which could later be tested with the experimental and survey data.

Experimental treatments for Stage 2 (Regulation).

The detailed experiments and treatment variables are explained in the table below, where:

$\mathbf{X}_{\mathbf{t}}$, is the level of extraction from the commons in round t. The decision on extraction is made individually and privately by each person.

$\mathbf{R}$, is the introduction of the regulation with a probability $p$ of inspection to a player, and a fine $f$ in case of non-compliance.

$\mathbf{V}$, is a voting process where the group decides by a majority of votes whether or not to introduce regulation with probability and fines $p$, $f$ announced by the experimenter before the vote.

For instance, $(\mathrm{X}-\mathrm{V}-\mathrm{R})_{11}$ means that in round 11 for this group, each player individually decides the level of extraction $\left(\mathrm{X}_{\mathrm{i}}\right)$ and her vote $\left(\mathrm{V}_{\mathrm{i}}\right)$ to apply the regulation in that round. Once the decisions are collected and the votes counted, the monitor applies the regulation (R), if 3 or more voted 'yes'. 


\begin{tabular}{|c|c|c|c|c|}
\hline \multicolumn{5}{|c|}{ Treatments design (Stages 1 and 2 ) } \\
\hline \multirow{2}{*}{$\begin{array}{c}\text { Experimental } \\
\text { treatments }\end{array}$} & \multirow{2}{*}{$\begin{array}{c}\text { Stage } 1 \\
\text { (10 rounds) }\end{array}$} & \multicolumn{3}{|c|}{ Stage 2 (10 rounds) } \\
\hline & & New rule & $\begin{array}{l}\text { (Round } \\
11)\end{array}$ & (Rounds 12-20) \\
\hline (X) Baseline & $\mathrm{X}_{1}, \mathrm{X}_{2}, \mathrm{X}_{3}, \ldots, \mathrm{X}_{10}$ & (No change - control) & $\mathrm{X}_{11}$ & $\mathrm{X}_{12}, \mathrm{X}_{13}, \ldots \ldots \ldots, \mathrm{X}_{20}$ \\
\hline $\begin{array}{l}\text { (XRL) Exogenous } \\
\text { Regulation } \\
\text { (Weak enforcement) }\end{array}$ & $\mathrm{X}_{1}, \mathrm{X}_{2}, \mathrm{X}_{3}, \ldots, \mathrm{X}_{10}$ & $\begin{array}{l}\text { Inspection of } 1 \text { player in each } \\
\text { round: } p=1 / 5, f=\$ 50\end{array}$ & $(\mathrm{X}-\mathrm{R})_{11}$ & $(\mathrm{X}-\mathrm{R})_{12},(\mathrm{X}-\mathrm{R})_{13}, \ldots \ldots \ldots,(\mathrm{X}-\mathrm{R})_{20}$ \\
\hline $\begin{array}{l}\text { (XRH) Exogenous } \\
\text { Regulation } \\
\text { (Strong enforcement) }\end{array}$ & $\mathrm{X}_{1}, \mathrm{X}_{2}, \mathrm{X}_{3}, \ldots, \mathrm{X}_{10}$ & $\begin{array}{l}\text { Inspection of } 1 \text { player in each } \\
\text { round: } p=1 / 5, f=\$ 175\end{array}$ & $(\mathrm{X}-\mathrm{R})_{11}$ & $(\mathrm{X}-\mathrm{R})_{12},(\mathrm{X}-\mathrm{R})_{13}, \ldots \ldots \ldots,(\mathrm{X}-\mathrm{R})_{20}$ \\
\hline $\begin{array}{l}\text { (VXRL) Endogenous } \\
\text { (voted) Regulation } \\
\text { (Weak enforcement) }\end{array}$ & $\mathrm{X}_{1}, \mathrm{X}_{2}, \mathrm{X}_{3}, \ldots, \mathrm{X}_{10}$ & $\begin{array}{l}\text { Inspection of } 1 \text { player in each } \\
\text { round: } p=1 / 5, f=\$ 50\end{array}$ & $(\mathrm{~V}-\mathrm{X}-\mathrm{R})_{11}$ & $(\mathrm{X}-\mathrm{R})_{12},(\mathrm{X}-\mathrm{R})_{13}, \ldots \ldots \ldots,(\mathrm{X}-\mathrm{R})_{20}$ \\
\hline $\begin{array}{l}\text { (VXRH) Endogenous } \\
\text { (voted) Regulation } \\
\text { (Strong enforcement) }\end{array}$ & $\mathrm{X}_{1}, \mathrm{X}_{2}, \mathrm{X}_{3}, \ldots, \mathrm{X}_{10}$ & $\begin{array}{l}\text { Inspection of } 1 \text { player in each } \\
\text { round: } p=1 / 5, f=\$ 175\end{array}$ & $(\mathrm{~V}-\mathrm{X}-\mathrm{R})_{11}$ & $(\mathrm{X}-\mathrm{R})_{12},(\mathrm{X}-\mathrm{R})_{13}, \ldots \ldots \ldots,(\mathrm{X}-\mathrm{R})_{20}$ \\
\hline
\end{tabular}

The sample of groups was distributed across treatments as follows:

\begin{tabular}{|c|c|c|c|c|}
\hline & \multicolumn{4}{|c|}{ Sample size by treatment } \\
\hline & \multicolumn{2}{|c|}{ Villagers } & \multicolumn{2}{|c|}{ Students } \\
\hline Experiment (treatment): & \# groups & \# people & \# groups & \# people \\
\hline (X) Baseline & 8 & 40 & 3 & 15 \\
\hline (XRL) Exogenous Regulation (Weak enforcement) & 20 & 100 & 5 & 25 \\
\hline (XRH) Exogenous Regulation (Strong enforcement) & 12 & 60 & 4 & 20 \\
\hline (VXRL) Endogenous Regulation (Weak enforcement) & 12 & 60 & 5 & 25 \\
\hline (VXRH) Endogenous Regulation (Strong enforcement) & 12 & 60 & 4 & 20 \\
\hline Sub-tota & 64 & 320 & 21 & 105 \\
\hline
\end{tabular}

\section{Results: Behavioral consequences of external regulations}

For presenting the experimental results and deriving some final insights from them, I will present a sequence of results that offer some lessons in at least two categories. First, there are methodological lessons regarding the use of economic experiments to explore questions that involve behavioral and psychological elements with policy implications. Secondly, there are lessons regarding the design and effects of external regulations aimed at producing socially desired outcomes, but with incomplete enforcement. 
According to the canonical model, the behavioural prediction for individuals maximizing their own material payoffs is that each chooses 8 units of extraction for a group extraction of 40 units. Such prediction is contrasted with the socially optimum level of group extraction of 5 units.

Let us first look at the experimental results for the mandatory regulations under a strong and weak fine mechanism. Figure 1 shows the evolution over rounds for the average group extraction under a sub-set of treatments that allows one to appreciate the first set of results. For clarity the data for the baseline treatments and for the mandatory regulations with low and high fines are included. The data for the regulations subject to a group vote will be shown and discussed later. All dotted lines in the figure represent data for the student groups, while the solid lines reflect the data for the field experiments conducted with villagers. Larger triangles represent the high fine (XHR) while smaller triangles represent data for the lower fine.

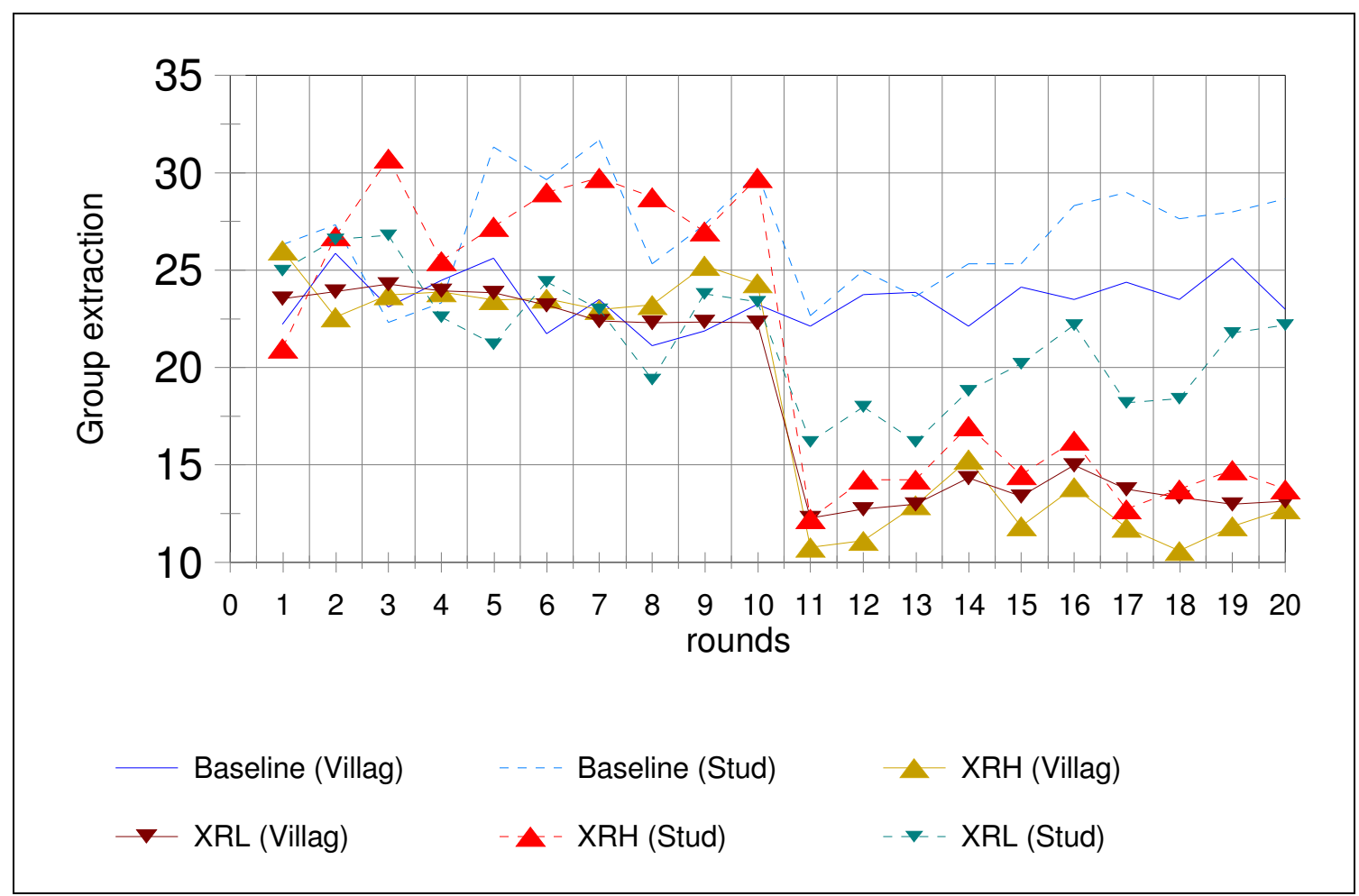

Figure 1. Average group extraction over time by treatments and subject pools.

\section{Result 1:}

Under a baseline treatment, players neither act accordingly to the canonical homo economicus model, nor achieve the socially optimum condition. Students and villagers do show a similar pattern of behavior under the baseline treatment, with a slight but statistically significant shift towards more cooperative behavior among the villagers. 
In Figure 1 the lines with no triangles represent the average group extraction for the baseline treatments. Throughout the rounds we can observe a slightly lower level of group extraction for the villagers (a Two-sample Wilcoxon rank-sum Mann-Whitney test yields a $\mathrm{p}$-value $=0.000$ when testing individual decisions data, and 0.0001 for group level data ${ }^{7}$. Given that the socially optimum level of group earnings in a round, according to the payoffs table, is $(758 \times 5)=3,790$ points, and that on average the students groups under the baseline treatments earned 2,498.3 and villagers groups earned on average 2,727.7, we find that students achieved a level of social efficiency of about $66 \%$ while villagers earned about $72 \%$, compared to the $42 \%$ of efficiency predicted at the Nash equilibrium of maximum feasible extraction. Further, while about $25 \%$ of the student decisions fell exactly within the predicted 8 units of extraction, only 14\% of these Nash choices were made by villagers. Later I will outline plausible explanations for this result, but in general it is more likely that the more experience villagers have of such situations the more it will induce them to refrain from over extracting. In fact we can observe a slight but steady trend towards higher extraction by students during the last rounds and a flatter trend for villagers.

\section{Result 2:}

There are positive effects of a partially enforced regulation based on a penalty on over-extraction, but the effect of the penalty level does not seem to fit the expected cost prediction (based on the expected utility model). Players seem to cooperate 'too much' under a low level of penalty, but they also seem to free-ride 'too much' under a higher penalty.

Continuing with Figure 1, we move now to the case of the externally imposed regulation with two variations. Under variation one, the weaker regulation (XRL), with a lower fine of $f=50$ points per unit above one unit of extraction, and a probability of inspection of $1 / 5$ in each round, should shift the material payoffs maximizers from 8 to 6 units, according to the model of expected costs described earlier. Under variation two, the stronger regulation $(\mathrm{XRH})$ with exactly the same conditions except for a fine of $f=175$ points would create an expected cost high enough to induce the players to choose the socially optimum condition of one unit of extraction, namely the same as their Nash strategy.

The results, presented in the graphs and descriptive statistics, suggest that such regulations do induce players to reduce their average level of extraction, particularly for the early rounds of the second stage. . Compared to baseline data in the $2^{\text {nd }}$ stage, all treatments under the weak or heavier regulations show a significant reduction in extraction. However, a few interesting phenomena deserve attention.

First, in both cases, low and high fine, the average villager shows a lower level of extraction during the $2^{\text {nd }}$ stage of the sessions. With the low fine (XRL), on average villagers chose about 1.173 units below the students, while in the case of the high fine (XRH) the difference is only 0.537 units although still significant. The 2-sample Wilcoxon rank-sum Mann-Whitney tests respectively yield pvalues of 0.0000 , and 0.0002 for individual level data and 0.0000 and 0.0086 for group level data. It is particularly interesting to note the early compliance by students under the low fine, and how their compliance decreases over time, almost reaching the level of extraction they were showing before the $2^{\text {nd }}$ stage of the game. 
It is also important to observe the small difference between the low and the high levels of fines, as compared with the prediction from the model that those under the high fine XRH, if choosing their best response, should play at the same level of the social optimum ( $x=1$ unit) while those under the low fine should choose 6 units of extraction. However, the difference with different levels of penalty is very small, and suggests that the players do not calculate the costs of regulations in the same manner. In fact the difference is substantially smaller for villagers than for students. On average over the rounds, villagers chose 0.34 units less under the high fine while students chose 0.981 units less under the same high fine. Recall that the predicted difference between the weak and the strong fine Nash strategy for players is 5 units, that is, 25 units of difference for the group extraction, between the two symmetric Nash equilibria. Apparently players under the low fine XRL seem to be cooperating more than they should, while those under the high penalty (XRH) seem to be attempting to capture rents by taking the chances of $4 / 5$ of not being inspected.

For both students and villagers the differences were statistically significant and in the expected direction, but the size of the difference, and the fact that it is smaller for the villagers, does suggest that our participants were following rules of thumb, suggested by the external authority - the experimenter in this case - in addition to their calculation of the benefits and costs of being inspected and regulated (see Cardenas, 2004a, for a further discussion of this phenomenon).

\begin{abstract}
Result 3:
When allowed to vote (VXRL, VXRH), the majority of villagers oppose the externally imposed regulations while the majority of students vote in favor of introducing them. Further, for the groups in which the majority favoured regulation, the average behavior was not different from the mandatory system of penalties (XRL, XRH).
\end{abstract}

The next set of treatments to be presented and discussed involve cases where the five players were asked to vote on whether they would like to face the regulation described for treatments XRL and $\mathrm{XRH}$ above. If 3 or more vote in favor, the regulation would be implemented in the same manner as in treatments XRL and XRH, but if 3 or more vote against such regulation, the session would continue in exactly the same manner as in the first stage for the remaining 10 rounds.

A first prediction is that all players would vote in favor of the regulation, even in the case of selfish and risk-taking players. The rationale is simple. Players should expect others to follow the new rule, and to take the risk of not being inspected and choose a higher level of extraction. The returns from such a decision would be substantial, according to the payoffs table. Notice that voting and enforcing these regulations are costless for all five players, and therefore the expected cost of the regulation is equivalent to the expected cost in the mandatory case, while the dominant strategy continues to be greater individual extraction up to the symmetric Nash equilibrium.

Let us first look at voting behavior at the group and individual level. The following table summarizes the number of groups that passed and failed to pass the votes among the villagers and among the students, for the two levels of penalties, high (VXRH) and low (VXRL). 


\begin{tabular}{|c|c|c|c|c|c|c|c|c|c|c|c|c|}
\hline & \multicolumn{6}{|c|}{$\%$ Groups that Passed the Rule } & \multicolumn{6}{|c|}{$\%$ Individual Votes } \\
\hline & \multicolumn{3}{|c|}{ Villagers } & \multicolumn{3}{|c|}{ Students } & \multicolumn{3}{|c|}{ Villagers } & \multicolumn{3}{|c|}{ Students } \\
\hline & No & Passed & Total & No & Passed & Total & $\mathrm{No}$ & Yes & Total & $\mathrm{No}$ & Yes & Total \\
\hline VXRH & $83 \%$ & $17 \%$ & 12 & $25 \%$ & $75 \%$ & $\overline{4}$ & $70 \%$ & $30 \%$ & 60 & $20 \%$ & $80 \%$ & 20 \\
\hline VXRL & $50 \%$ & $50 \%$ & 12 & $40 \%$ & $60 \%$ & 5 & $58 \%$ & $42 \%$ & 60 & $36 \%$ & $64 \%$ & 25 \\
\hline Total & $67 \%$ & $33 \%$ & 24 & $33 \%$ & $67 \%$ & 9 & $64 \%$ & $36 \%$ & 120 & $29 \%$ & $71 \%$ & 45 \\
\hline
\end{tabular}

Clearly, students were more prone to ask for these regulations than the villagers. Among the villagers, in $67 \%$ of the 24 groups of villagers, the majority voted against the regulations at the group level and 64\% voted against regulations at the individual level. Among the students, however, 67\% favoured regulation at the group level, and $71 \%$ favoured regulations at the individual level. Also, there are some interesting differences across levels of penalties. Villagers were especially opposed to high fines while students were more inclined to vote for them. These results were confirmed at the community workshops we held days later in these villages, where high fines were regarded as too high and unnecessary.

If we look at individual voting, by subject pool and treatment (See Table 4 below) we observe how for villagers (the two first rows) only two groups obtained a total of 4 votes and none had all 5 votes in favor of regulation. In contrast, 6 out of the 9 sessions for students got 4 or more votes.

\begin{tabular}{|c|c|c|c|c|c|c|c|}
\hline \multicolumn{7}{|c|}{ Frequency of Groups by Individual Votes } \\
\cline { 2 - 9 } & $\mathbf{0}$ & $\mathbf{1}$ & $\mathbf{2}$ & $\mathbf{3}$ & $\mathbf{4}$ & $\mathbf{5}$ & $\begin{array}{c}\text { Total } \\
\text { groups }\end{array}$ \\
\hline VXRH-Villagers & 2 & 4 & 4 & 2 & & & 12 \\
\hline VXRL-Villagers & 3 & 1 & 2 & 4 & 2 & & 12 \\
\hline VXRH-Students & & & 1 & & 1 & 2 & 4 \\
\hline VXRL-Students & & 1 & 1 & & 2 & 1 & 5 \\
\hline \hline
\end{tabular}

Nevertheless, this difference in aversion to external regulations contrasts with the opposite intentions in choices. We have already observed in the previous results that not only did the villagers show a slightly more cooperative behavior for the baseline, but that their compliance with the suggested regulation was on average higher than among the students, despite their lower votes in favor of such enforcement. In the next result I will explore the individual decisions (extraction), comparing groups that did not pass the regulation and those that did with 3 or more votes.

Result 4:

Players voting against the external regulation showed a significant willingness to cooperate under the suggested new rule. However, negative reciprocity and the absence of any other coordination mechanism generated a partial erosion of 


\section{these group oriented motivations, although still producing socially superior}

results than the first stage.

Figures 2 and 3 below describe the evolution of group extraction over rounds for all the sessions in which voting took place (VXRL and VXRH). Figure 2 describes the behavior of those groups in which the majority voted against the regulation and therefore continued after round 11 under the same conditions as during the $1^{\text {st }}$ stage. In other words, material incentives would be equivalent to the baseline treatment. Figure 3 illustrates the case of those groups that approved the regulation and therefore faced a penalty that had a probability of being enforcement.

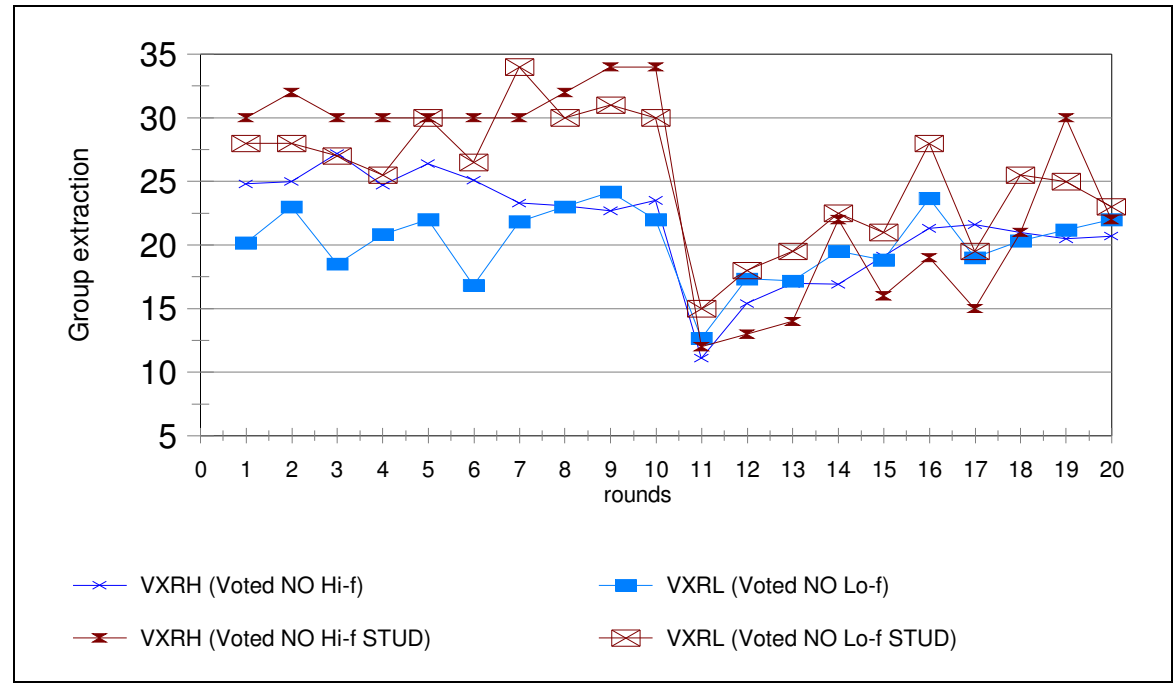

Figure 2. Average group extraction for groups that did NOT pass the proposed regulations

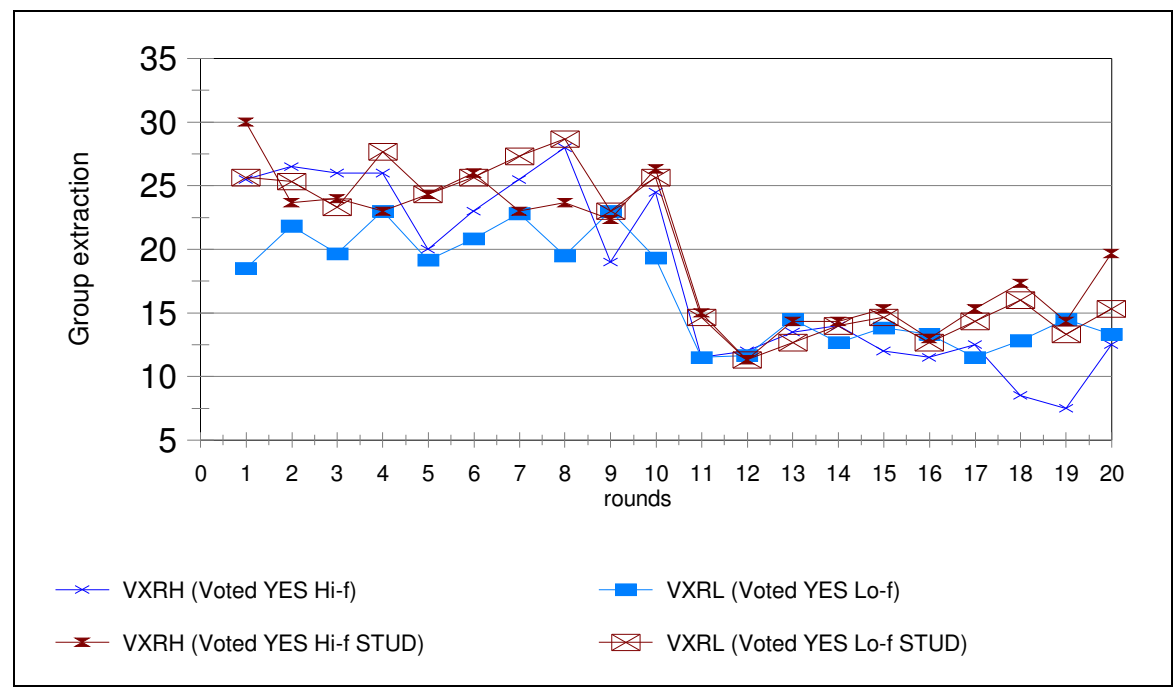

Figure 3. Average group extraction for groups that DID pass the proposed regulations 
The behavioral effects of the regulations warrant some discussion. First of all, as in the previous analysis it seems that the effect of lower or higher fines does not create very large differences in behavior. Whether the fine is of 50 points or 175 points, the average group effect is similar.

Two interesting phenomena, however, seem to occur where regulations are subject to a group vote. First, all players, regardless of whether they approve or reject the regulation, showed a significant decrease in extraction by round 11 and for the subsequent few rounds. Notice that before the decision is made in round 11, all groups were told of the purpose of the new rule. Second, by the end of round 11 they learnt if the regulation was to be implemented for the rest of the session. The willingness of the participants (whether students or villagers) to cooperate, emerges as an effect of the norm 'proposed' by the external regulator, namely, the monitor who announced out loud to the group that the purpose of the new regulation being proposed was to achieve maximum earnings for the group.

Therefore, all groups witnessed a strong shift towards the group maximizing outcome regardless of the voting. Further, the average player among the groups that did not pass the rule still showed a willingness to follow the group maximizing strategy. However, there was an erosion of cooperation among these groups that did not pass the regulation, after the first round of attempts at a nonbinding low level of extraction, while the groups under the approved regulation maintained the lower levels of extraction over the rounds. The more plausible explanation for this behavior is the triggering of negative reciprocity by players who witnessed other players to be extracting more than was suggested, and therefore using their own increase in extraction either as a punishing device or at least to avoid the sucker's payoff, which has been consistently found in the literature. Nevertheless, all groups that did not pass the vote ended the $2^{\text {nd }}$ stage under lower levels of extraction than at the end of their $1^{\text {st }}$ stage.

Now comparing the subject pools, for cases that did not approve the regulation, we find no significant differences, but for the approved sessions, villagers on average, at the end of the $2^{\text {nd }}$ stage, showed a slightly lower level of group extraction ${ }^{8}$. Recall that villagers were less prone than students to vote in favor of such regulations and these regulations were approved in only a few villages.

\section{Enriching experiments with other field techniques}

The additional field work tools can help explain some of the results and puzzles just presented, particularly with respect to bias against regulations and yet a willingness to reduce extraction in the experiment. The workshops and follow-up field interviews we conducted after the end of the experiments in each village allowed us to discuss the low voting in favor of a rule that would clearly increase players earnings. It also helped us to explore why players on average reduced their extraction even where the group voted to continue playing under the same rules as in the first stage. The analogies with the actual context of rules and presence of regulating agencies were clear. By exploring the differences across the three villages we could deepen this analysis.

In general, a majority of village groups were against the regulations, but there were some differences across sites that were discussed during the community workshops in which we used rapid rural appraisal techniques. In general, in only 8 out of the 24 village groups did the majority vote in favor 
of the regulation, while among the students the ratio was 6 out of 9 . In terms of individual votes, 32 students out of 45 voted in favor, while only 43 of the 120 villagers did so.

Consider in more detail the three villages where the voting took place. In Neusa, only 1 out of 8 groups had a majority vote, in Sanquianga 4 out of 8 groups voted in favor, and in LaVega 3 of the 5 groups voted in favor of the different rules. During the workshops we used some tools to study, in each case, the relations of external actors with the community of resource users, including state and non-government organizations. Neusa represented the most conflict-ridden case of a close but negative relation with the Corporacion Autonoma Regional, the environmental agency in charge of monitoring and controlling the use and extraction of resources. For instance, in Neusa the regulatory agency had hired a private security company to monitor the fishermen's catch every day. In LaVega the regulatory agency was basically absent as far as the villagers were concerned and was replaced by a non-government organization, the regional federation of coffee growers, whose role was to provide support and technical assistance rather than to regulate. In Sanquianga, again, the regional authority was absent; instead there was the National Parks System (Ministry of Environment) with a closer but more positive relation with the community of fishermen and clam gatherers, given its lack of resources, funding and weak political clout for enforcing rules through monitoring and sanction.

\section{Discussion and conclusions.}

There is surprisingly little work on the behavioral response of individuals to externally imposed regulations, such as those imposed by state agencies, that issue rules that are aimed at maximizing social welfare but that can only partially enforce compliance. Also, the experimental literature still needs to open the debate when finding behavioral differences across subject pools. Such a debate could enrich the understanding of phenomena we find in the economic lab.

The experimental work presented in this paper, conducted in the lab with students and in the field with villagers that have joint access to a natural resource, is aimed at filling these gaps to some extent. By comparing these two different subject pools we observe similar behavior, but with a statistically significant difference in attitudes toward externally imposed regulations. The villagers rejected such regulations more often than students when allowed to vote for their implementation, but were more willing to cooperate under a non-binding setting.

The results leave some puzzles unsolved and in fact open new questions for research. How rules affect behavior and therefore outcomes cannot be explained easily through the basic game-theoretic model of maximizing material incentives, or the use of expected utility theory. At least in our experimental results, individuals respond to more factors than just the expected cost of regulations. Our field evidence and our discussions and workshops with the field participants, also indicate that there is a bias against the imposition of regulations that can clearly help each group member increase her/his earnings. Our field discussions also suggest that the effect of state regulators can often be negative in terms of inducing a self-governed solution to the commons dilemma, particularly where regulation by the state is costly and difficult.

As one of the women - a gatherer of mollusks in the Sanquianga mangrove forest region - said at the end of her session in which we allowed the group to vote for the regulation, 'I didn't want the rule or 
the penalty, but I do want to pick the large ones only", referring to how by picking only the large clams the resource could naturally reproduce and maintain a sustainable yield. In her case, as in several others, the second stage showed a decrease in extraction even though the majority voted against the regulation.

The differences in behavior and outcomes between students and villagers can also open new methodological implications for experimental research. I believe these two are complementary and not necessarily contradictory. It seems that student behaviour is slightly closer to the gametheoretical predictions. If this is indeed the case, we need to discuss the implications further. Often experimental studies are designed to illustrate policy design. If conducted only with students, without replication in the field with subjects that are familiar with the problem in practical terms, the studies can miss relevant information. Further, some experiments can be used to enlighten policy designs which are more likely to be applied to people in the field than to students.

In this sense, the field can help explain the variations across and within groups observed in many of these experiments. Having the villagers participate in the research, by discussing with the research team the preliminary data from the experiments, helped us clarify some of the key puzzles. By comparing the villages and the particular context in which the participants face external regulations from state agencies and other actors, we pose plausible differences in the fraction of players voting in favor of experimental regulations. I discuss elsewhere (Cardenas, 2004b) how bringing the lab to the field can enrich our experimental work, as people in experiments bring with them information in the form of clues or rules of thumb based on their own experience in similar situations. In the field experiments, the context of our villagers is definitely providing some hints to our participants during the game, as they clearly explained to us in our interviews and workshops. The context and prior experience of students is different from that of the villagers leading to behavioural differences in the experiments. This brings us to the last issue, namely the rich information that can emerge when we combine experimental work in the field with that in the university lab. This would make the policy conclusions derived from experiments broader and more relevant than if only students are used as subject pools, as has been typical of behavioural economics to date. 


\section{References}

Andreoni, James, William T. Harbaugh and Lise Vesterlund (2003) "The Carrot or the Stick: Rewards, Punishments and Cooperation." American Economic Review, 93(3), June 2003, 893-902.

Baland, Jean-Marie and Jean-Philippe Platteau (1996) "Halting degradation of natural resources : is there a role for rural communities?”. New York : Oxford University Press, 1996.

Berkes, Fikret (ed.) Common Property Resources: Ecology and Community-Based Sustainable Development. London: Belhaven Press. (1989a).

Bohnet, Iris, Bruno S. Frey, and Steffen Huck (2001). "More Order with Less Law: On Contract Enforcement, Trust, and Crowding". American Political Science Review Vol. 95, No. 1 March 2001.

Bowles, Samuel. 1998. Endogenous Preferences: The Cultural Consequences of Markets and Other Economic Institutions. Journal of Economic Literature 36 (March): 75-111.

Camerer, C. and E. Fehr (2004). Measuring social norms and preferences using experimental games: A guide for social scientists. Foundations of human sociality: Experimental and ethnographic evidence from 15 small-scale societies. J. Henrich, R. Boyd, S. Bowleset al, Oxford University Press.

Cardenas, Juan Camilo (2004a) "Norms from Outside and from Inside: An Experimental Analysis on the Governance of Local Ecosystems”. Forest Policy and Economics, 6 (2004): 229-241. Elsevier Press

Cardenas, Juan Camilo (2004b) "Bringing the Lab to the Field: More Than Changing Subjects" Paper presented at the International Meeting of the Economic Science Association, Pittsburgh, June, 2003. Available at: http://pwp.007mundo.com/cardenasramirez/CardenasMore'ThanChangingSubjects.pdf

Cardenas, Juan Camilo, John K. Stranlund and Cleve E. Willis (2000) "Local Environmental Control and Institutional Crowding-out". World Development, October, Vol 28, No. 10. pp. 1719-1733.

Carpenter, Jeffrey (2004) "Punishing Free-Riders: how group size affects mutual monitoring and the provision of public | goods". Forthcoming, Games and Economic Behavior. Available at: http://community.middlebury.edu/ jcarpent/papers/PFR(revision).pdf

| Carpenter, Jeffrey and Peter Mathews (2004) "Social Reciprocity". Mimeo. Available at: http://community.middlebury.edu/ jcarpent/papers/SR(2004).pdf

Cason, Timothy N. and Feisal U. Kahn (1999). "A laboratory study of voluntary public goods provision with imperfect monitoring and communication”. Journal of Development Economics. Vol. 58 (1999) 533-552.

Ensminger, J. (2000). Experimental economics in the bush: Why institutions matter. In Institutions, contracts, and organizations: Perspectives from new institutional economics. C. Menard Ed. London, Edward Elgar: 158-171.

Falkinger, Josef, Ernst Fehr, Simon Gachter, And Rudolf Winter-ebmer (2000). “A Simple Mechanism for the Efficient Provision of Public Goods: Experimental Evidence. American Economic Review, 90(1): 247-264.

Fehr, Ernst and David Schmidt (1999) “A Theory of Fairness, Competition, and Cooperation”. Quarterly Journal of Economics, 114(1999):817-851.

Fehr, Ernst and Simon Gachter (2000) “Do Incentive Contracts Crowd Out Voluntary Cooperation?”. Institute for Empirical Research in Economics, University of Zürich, Working Paper No. 34. Available at:

http://www.iew.unizh.ch/wp/iewwp034.pdf 
Gintis, Herbert (2000), "Beyond Homo economicus: evidence from experimental economics”, Ecological Economics, 35 (2000) 311-322.

Henrich, Joseph, Robert Boyd, Samuel Bowles, Colin Camerer, Ernst Fehr, Herbert Gintis, and Richard McElreath (2001). "Cooperation, Reciprocity and Punishment in Fifteen Small-scale Societies". American Economic Review 91 (May 2001): 73-78.

Kahneman, Daniel and Amos Tversky (editors) (2000). "Choices, Values and Frames". Cambridge University Press Russell Sage Foundation. 2000.

Loewenstein, George (1999) “Experimental Economics From the Vantage Point of Behavioural Economics". The Economic Journal. 109 (February), F25-F34.

Ostrom, Elinor (1990). "Governing the Commons: The evolution of institutions for collective action". Cambridge ; New York : Cambridge University Press, 1990.

Ostrom, Elinor et.al, editors (2002) “The Drama of the Commons”. Committee on the Human Dimensions of Global Change. National Academy Press. Washington.

Ostrom, Elinor, James Walker and Roy Gardner (1992). "Covenants with and without a Sword: Self-governance is possible”. American Political Science Review. Vol. 86, No. 2. June 1992.

Ostrom, Elinor, Roy Gardner and James Walker (1994). "Rules, games and Common-Pool Resources". U.Michigan Press. Ann Arbor. 1994.

Rabin, Mathew (1998) "Psychology and Economics,". Journal of Economic Literature, Vol. XXXVI (March 1998), pp. 11-46.

Rabin, Matthew (2002) “A perspective on psychology and economics. Alfred Marshall Lecture”. European Economic Review 46 (2002) $657-685$.

Sefton, Martin, Robert Shupp and James Walker (2002) "The Effect of Rewards and Sanctions in Provision of Public Goods". Mimeo. 


\section{APPENDIX}

A-1. Payoffs table experimental design

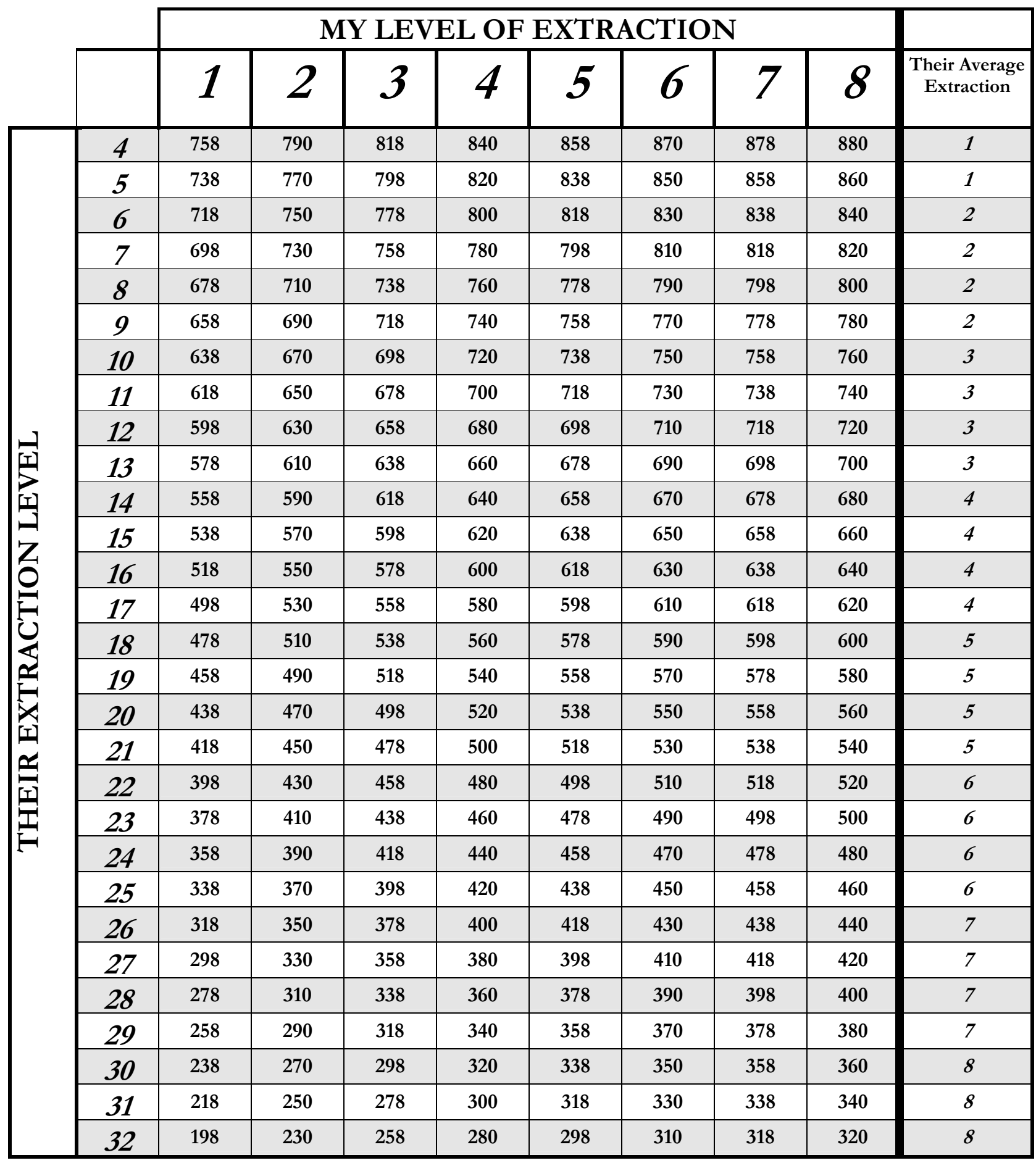




\section{Experiment instructions (English translation).}

These instructions were originally written in Spanish and translated from the final version used in the field work. The instructions were read to the participants from the script below by the same person during all sessions. The participants could interrupt and ask questions at any time.

Whenever the following type of text and font e.g. [...MONITOR: distribute PAYOFFS TABLE to participants...] is found below, it refers to specific instructions to the monitor at that specific point; when in italics, these are notes added to clarify issues to the reader. Neither of these were read to participants. Where the word "poster" appears, it refers to a set of posters we printed in very large format with the payoffs table, forms, and the three examples described in the instructions. These posters were hung on a wall near the participants' desks where the 8 people could see them easily.

\section{COMMUNITY RESOURCES GAME (Instructions)}

Greetings...

We want to thank every one here for attending the call, and specially thank the field practitioner (name of the contact

person in that community), and (local organization that helped in the logistics) who made this possible. We will spend about two hours between explaining the exercise, playing it and finishing with a short survey at the exit. So, let us get started.

The following exercise is a different and entertaining way of participating actively in a project about the economic decisions of individuals. Besides participating in the exercise, and being able to earn some prizes and some cash, you will participate in a community workshop in two days to discuss the exercise and other matters about natural resources. During the day of the workshop we will give you what you earn during the game. The funds to cover these expenditures have been donated by various international organizations and the University.

\section{Introduction}

This exercise attempts to recreate a situation where a group of families must make decisions about how to use the resources of, for instance, a forest, a water source, a mangrove, a fishery, or any other case where communities use a natural resource. In the case of this community ___ (name of the specific village), an example would be the use of firewood or logging in the (name of an actual local commons area in that village) zone. You have been selected to participate in a group of five people among those that signed up for playing. The game in which you will participate now is different from the ones others have already played in this community, thus, the comments that you may have heard from others do not apply necessarily to this game. You will play for several rounds equivalent, for instance, to years or harvest seasons. At the end of the game you will be able to earn some prizes in kind and cash. The cash prizes will depend on the quantity of points that you accumulate after several rounds.

\section{The PAYOFFS TABLE}

To be able to play you will receive a PAYOFFS TABLE equal to the one shown in the poster. [...MONITOR: show PAYOFFS TABLE in poster and distribute PAYOFFS TABLE to participants...]

This table contains all the information that you need to make your decision in each round of the game. The numbers that are inside the table correspond to points (or pesos) that you would earn in each round. The only thing that each of you has to decide in each round is the LEVEL OF EXTRACTION that you want to allocate extracting resources(in the columns from 1 to 8$)$.

To play in each round you must write your decision number between 1 and 8 in a yellow GAME CARD like the one I am about to show you. [...MONITOR: show yellow GAME CARDS and show in the poster...] It is very important that we keep in mind that the decisions are absolutely individual, that is, that the numbers we write in the game card are private and that we do not have to show them to the rest of members of the group if we do not want to. The monitor will collect the 5 cards from all participants, and will add the total units of extraction that the group decided to allocate. 
When the monitor announces the group total, each of you will be able to calculate the points that you earned in the round. Let us explain this with an example.

In this game we assume that each player extract as maximum of 8 units of a resource like firewood or logs. In reality this number could be larger or smaller but for purposes of our game we will assume 8 as maximum. In the PAYOFFS TABLE this corresponds to the columns from 1 to 8 . Each of you must decide from 1 to 8 in each round. But to be able to know how many points you earned, you need to know the decisions that the rest in the group made. That is why the monitor will announce the total for the group in each round. For instance, if you decide to extract 2 units and the rest of the group together, add to 20 units, you would gain points. Let us look at two other examples in the poster.

[...MONITOR: show poster with the THREE EXAMPLES...]

Let us look how the game works in each round.

\section{The DECISIONS FORM}

To play each participant will receive one green DECISIONS FORM like the one shown in the poster in the wall. We will explain how to use this sheet. [...MONITOR: show the DECISIONS FORM in the poster and distribute the DECISIONS FORMS...]

With the same examples, let us see how to use this DECISIONS FORM. Suppose that you decided to play 5 units in this round. In the yellow GAME CARD you should write 5. Also you must write this number in the first column A of the decisions form. The monitor will collect the 5 yellow cards and will add the total of the group. Suppose that the total added 26 units. Thus, we write 26 in the column B of the decisions form. [...MONITOR: In the poster, write the same example numbers in the respective cells...]

To calculate the third column (C), we subtract from the group total, MY DECISION and then we obtain THEIR LEVEL OF EXTRACTION which we write in column C. In our example, $26-5=21$. If we look at the PAYOFFS TABLE, when MY EXTRACTION are 5 and THEIR EXTRACTION are 21, I earn __ points. I write then this number in the column D of the DECISIONS FORM.

It is very important to clarify that nobody, except for the monitor, will be able to know the number that each of you decides in each round. The only thing announced in public is the group total, without knowing how each participant in your group played. Let us repeat the steps with a new example. [...MONITOR: Repeat with the other two examples, writing the numbers in the posters hanging in the wall...]

It is important to repeat that your game decisions and earnings information is private. Nobody in your group o outside of it will be able to know how many points you earned or your decisions during rounds. We hope these examples help you understand how the game works, and how to make your decisions to allocate your UNITS OF EXTRAC TION in each round of the game. If at this moment you have any question about how to earn points in the game, please raise your hand and let us know.

[...MONITOR: pause to resolve questions...]

It is very important that while we explain the rules of the game you do not engage in conversations with other people in your group. If there are no further questions about the game, then we will assign the numbers for the players and the rest of forms needed to play.

\section{Preparing for playing:}

Now write down your player number in the green DECISIONS FORM. Write also the place and the current date and time ____________ am/pm. In the following poster we summarize for you the steps to follow to play in each round. Please raise your hand if you have a question.

[MONITOR: Read the steps to them from the poster]

Before we start, and once all players have understood the game completely, the monitor will announce one additional rule for this group. To start the first round of the game we will organize the seats and desks in a circle where each of you face outwards. The monitor will collect in each round your yellow game cards. Finally, to get ready to play the game, please let us know if you have difficulties reading or writing numbers and one of the monitors will seat next to you and assist you with these. Also, please keep in mind that from now on no conversation or statements should be made by you 
during the game unless you are allowed to. We will first have a few rounds of practice that will NOT count toward your real earnings, they are just for your practicing the game. 
${ }^{1}$ This research was made possible through a Research \& Writing Grant from the John D. and Catherine T. Macarthur Foundation and a grant from the Network on Social Norms and Preferences headed by Herbert Gintis and Robert Boyd. I thank them for their support. Thanks are also due to Ernst Fehr in particular for providing important insights for the experimental design; to the Santa Fe Institute for an International Fellowship, and to the School of Environmental and Rural Studies at Javeriana University (Colombia) during my field work. I also thank Maria Claudia Lopez, Pablo Ramos and Ana María Roldán for assistance in the field and in processing data. Diana Maya provided important inputs in the analysis of qualitative data. I am also grateful to Maria Alejandra Velez and the editors of this volume for their valuable comments that helped improve this manuscript.

${ }^{2}$ The experimental design and treatments were inspired by previous results (Cardenas, et.al 2000) where similar experiments in the field produced the intriguing result of a crowding-out of group oriented preferences.

${ }^{3}$ An analysis of the experimental data across sites goes beyond the scope of this paper.

${ }^{4}$ This paper does not deal with other objective functions for the planner or regulator, such as private or political rent-seeking behavior.

${ }^{5}$ See e.g. Falkinger, Fehr, Gachter and Winter-Ebmer (2000); Fehr and Gachter (2000); Sefton, Shupp and Walker, (2000); Ostrom, Gardner and Walker (1994); Ostrom, Walker and Gardner (1992); Bohnet, Frey and Huck (2001); and Cason and Kahn (1999).

${ }^{6}$ Evidence from other experiments conducted in the field is growing (Henrich, 2000; Henrich et.al, 2001;

Ensminger, 1999) but so far such experiments have not tested regulations aimed at correcting individual behavior. For recent conferences on the use of field experiments, see: http://www.middlebury.edu/depts/econ/conference/conference_2003/index_2003.shtml and http://www.cirano.qc.ca/experimentaleconomics/esa/

${ }^{7}$ Individual level tests are using individual choices in each round as observations; group level tests are conducted with group totals in each round serving as observations.

${ }^{8}$ Only in the case of high penalty that passed the vote (VXRH (voted YES hi-f) is there a significant difference with villagers showing a lower level of group extraction. 